se na anamnese, exame físico, exame histopatológico e testes de imunofluorescência. $\mathrm{O}$ tratamento do penfigóide bolhoso canino é freqüentemente dificil, necessitando de grandes doses de glicocorticóides sistêmicos, associados ou não a outros fármacos imunomoduladores potentes, como a azatioprina, o clorambucil e a ciclofosfamida. O glicocorticóide de escolha é a prednisolona ou a prednisona. O prognóstico varia de acordo com a extensão das lesões e casos não tratados podem ser fatais. $O$ presente trabalho relata o caso de um animal da espécie canina, raça Cocker Spaniel, fêmea, com três anos de idade, levada à consulta no Hospital Veterinário da UFPR por apresentar lesões de pele, prurido intenso, opacidade corneana e hiporexia. Ao exame fisico foram observadas lesões de pele ulceradas, exsudativas, eritematosas e crostosas em abdome, virilha, axilas, tórax, membros e leito ungueal. Foram verificadas lesões eritematosas e ulceradas em vulva e língua e úlcera de córnea no olho direito. Realizou-se biópsia das lesões e exame histopatológico de três fragmentos de pele, os quais exibiram o mesmo padrão lesional, demonstrando a presença de dermatite vesicular subepidermal. O hemograma revelou leucocitose, neutrofilia, desvio de neutrófilos à esquerda, bastonetes e segmentados tóxicos. Estabeleceu-se o diagnóstico de penfigóide bolhoso através do resultado do exame histopatológico associado aos sinais clínicos. Instituiu-se o tratamento com prednisona $(2 \mathrm{mg} / \mathrm{kg})$ a cada vinte e quatro horas, enrofloxacina $(5 \mathrm{mg} / \mathrm{kg})$ a cada doze horas, colírio de cloranfenicol quatro vezes ao dia e pomada oftálmica a base de cloranfenicol, aminoácidos, vitamina A e metionina, a cada 12 horas. O tratamento inicial foi realizado durante doze dias, verificando-se grande melhora das lesòes de pele, leito ungueal, mucosa vulvar e úlcera de córnea, além de ausência do prurido. Verificou-se, porém, pouca redução da lesão em língua. $\mathrm{O}$ tratamento com prednisona, colírio e pomada oftalmológica foram mantidos durante um mês, observando-se total recuperação da úlcera de córnea e das lesões de pele, exceto duas lesões, sendo uma em região cervical e outra em região do queixo, melhora das lesões em língua e ausência de lesões em mucosa vulvar e leito ungueal. Indicou-se manter a dose de prednisona e aumentar a frequência para cada doze horas, sendo que na reavaliação ainda persistiam as mesmas lesões de pele e língua. A dose de prednisona foi aumentada $(4 \mathrm{mg} / \mathrm{kg})$ e marcada reavaliação após dez dias, verificando-se melhora da lesão do queixo, porém persistência das demais lesões e surgimento de nova lesão ulcerativa em região torácica dorsal. Foi indicado ao proprietário manter a medicação prescrita por mais dez dias, até a próxima avaliação e conforme a evolução das lesōes instituir a associaçào de outras medicações ao tratamento, porém o proprietário não retornou com a paciente para a reavaliação. Pode-se concluir que o penfigóide bolhoso deve ser considerado no diagnóstico diferencial de diversas manifestações dermatológicas ulcerativas, sendo de grande importância o exame histopatológico para o diagnóstico definitivo. Alguns cães podem responder bem a baixas doses de corticóides, enquanto outros animais podem se mostrar resistentes, como o cão do caso relatado, necessitando de associação a outras medicações imunomoduladoras e, algumas vezes, de tratamento por toda a vida do paciente. A colaboração do proprietário é imprescindivel para o sucesso do tratamento e controle da doença.

\title{
33 - Pênfigo foliáceo em canino jovem. Relato de caso
}

Castro, R.C.C'; Marcondes Santos, M. ${ }^{2}$; Gussoni F. R. A. ${ }^{2}$; Fragata, F. S. ${ }^{2}$
1- Departamento de Dermatologia do Hospital Veterinário Sena Madureira, São Paulo-SP

2- Departamento de Clinica Médica do Hospital Veterinário Sena Madureira, São Paulo-SP

O complexo pênfigo constitui um grupo de enfermidades auto-imunes raras, da ordem de $0,3 \%$ que incluem o pênfigo foliáceo, o pênfigo vulgar e o pênfigo eritematoso. São desordens cutâneas vésico-bolhosas, erosivas e ulcerativas, descritas no homem, cão e gato e que podem acometer não somente o tegumento, mas também as membranas mucosas. As lesões clássicas são aquelas do grupo das coleções líquidas (pústulas e vesículas), levando à formação de lesões erosadas, crostosas, normalmente melicéricas, assestando-se preferencialmente na face, nos pavilhões auriculares, regiào inguinal e no tronco do animal. 
A hiperqueratose de coxins palmares e/ou plantares pode ser observada. Em relação a sintomatologia, podem ser observadas: hipertermia, prostração, anorexia e perda de peso, bem como, graus variados de algia e o prurido cutâneo pode ou não estar presente. Os achados citológicos podem ser sugestivos, porém o cabal diagnóstico, baseia-se nos achados histopatológicos. Um animal da espécie canina, raça Lhasa-Apso, de cerca de um ano de idade foi atendido no Hospital Veterinário Sena Madureira, com quadro evoluindo há 15dias, caracterizado por prostração intensa, meneios cefálicos inciado tão logo a realização de imunização habitual por profissional veterinário.Como alterações ao exame fisico evidenciouse elevação da temperatura corporal, bem como lesões pustalares e vesículas em região abdominal ventral e densas crostas melicéricas recobrindo áreas erosadas em face interna de pavilhòes auriculares. Os coxins palmares e plantares apresentavam-se hiperqueratóticos e em alguns pontos ulcerados com a eliminação de material piosanguinolento à expressão. Nào foram observadas lesões nas mucosas oral, peniana e anal. Foi realizado hemograma, mensuração sérica de FA, TGO e TGP e parasitológico de raspado cutâneo, todos dentro da normalidade. Ao exame citológico de material presente em uma pústula, não foram evidenciadas bactérias, mas a presença de grande quantidade de neutrófilos, aventando-se a possibilidade de se tratar de um quadro auto-imune. Optou-se pela realização de biópsia cutânea (punch de Keys) com a remoçào de fragmento contendo lesão pustular íntegra, onde ao exame histopatológico (coloração habitual HE), foi observada a presença de pústulas subcorneais e de numerosas células acantolíticas (células de Tzanc), tratando-se portanto, de um quadro de pênfigo foliáceo. Estabelecido o diagnóstico, foi instituída terapia com corticóide sistêmico, à base de prednisolona $\left(\right.$ Meticorten $^{\circ}$ ). Após 15 dias de terapia, as lesões cutâneas haviam regredido totalmente, o animal apresentava-se normotérmico e com excelente estado geral, nesta ocasião mostrava sintomas atribuidos a administração de esteróides, como polidipsia e aumento da quantidade e frequência de micção. Foi realizada diminuição gradativa do medicamento referido. Atualmente, o animal recebe predinisona com intervalo de três dias de administração e na dose de $0,5 \mathrm{mg} /$ $\mathrm{kg}$ de peso, nào apresentando qualquer alteração sistêmica e/ou tegumentar. $\mathrm{O}$ objetivo do relato é descrever um caso numa faixa etária pouco habitual de assestamento desta enfermidade auto-imune, visto que o complexo pênfigo acomete, mais frequentemente animais com idade média. Deve-se ressaltar ainda, a importância, a que todos os clínicos devem dispensar, em incluir o pênfigo, principalmente o foliáceo, naquelas enfermidades vesico-bolhosas e pustulares, especialmente àquelas que não cedem a antibioticoterapia

\section{4 - Aspectos ultra-sonográficos modo B, doppler colorido e power doppler nas alterações focais e/ou multifocais do parênquima esplênico de cães com suspeita de processos neoplásicos não linfóides}

Iwasaki, M.'; Froes,T.R. ${ }^{2}$;

Torres.L.N." ${ }^{3}$; Castro,P.F.";

Galeazzi,V.S. ${ }^{3}$; Cortopassi,S.R.G. ${ }^{4}$;

Guerra, J.L. ${ }^{5}$
1- Professor Titular do Departamento de Cirurgia da Faculdade de Medicina Veterinária da Universidade de São Paulo, São Paulo-SP

2- Doutoranda do Departamento de Cirurgia da Faculdade de Medicina Veterinária da Universidade de São Paulo, São Paulo-SP

3- Médicas Veterinárias do Hospital Veterinário da Faculdade de Medicina Veterinária da Universidade de São Paulo, São Paulo-SP

4- Professora Doutora do Departamento de Cirurgia da Faculdade de Medicina Veterinária da Universidade de São Paulo, São Paulo-SP

5- Professor Titular do Departamento de Patologia da Faculdade de Medicina Veterinária da Universidade de São Paulo, São Paulo-SP

O exame ultra-sonográfico do baço tem como principal indicação descartar processos neoplásicos em animais portadores de esplenomegalia ou massas em região esplênica, detectadas à palpação ou exame radiográfico. As neoplasias malignas primárias do baço mais 